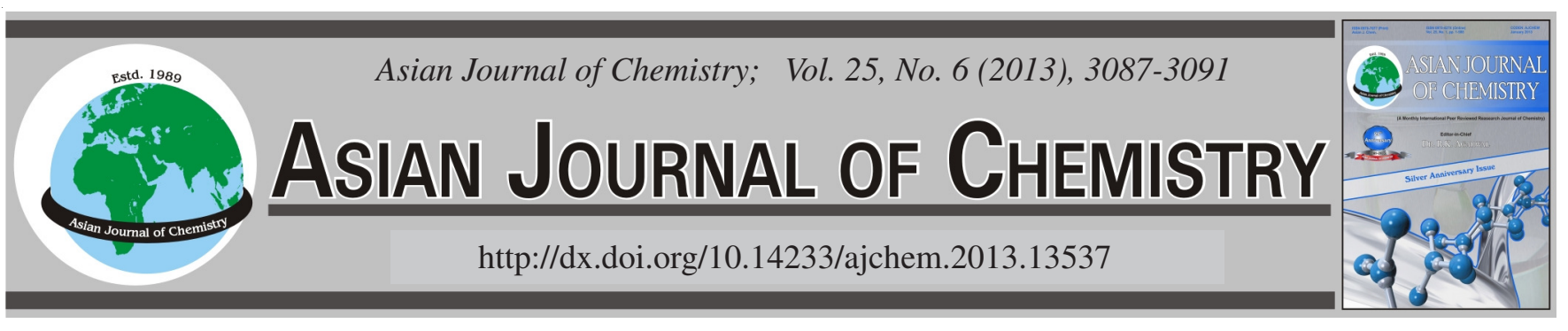

\title{
Effect of Phase Transitions Between $\alpha$-Tricalcium Phosphate and $\beta$-Tricalcium Phosphate on the Setting Properties of Novel Strontium-Containing Bioactive Bone Cement
}

\author{
Zhaoyao Sun ${ }^{1, \dagger}$, YuANFeI Fu ${ }^{2, \dagger}$ and Demin CHeN $^{1, *}$
}

${ }^{1}$ Shanghai Biomaterials Research \& Testing Center, Shanghai Key Laboratory of Stomatology, Ninth People's Hospital, Shanghai Jiaotong University School of Medicine, No. 427, Ju-men Road, Shanghai 200023, P.R. China

${ }^{2}$ Department of Prosthodontics, School of Stomatology, Ninth People's Hospital, School of Medicine, Shanghai Jiao Tong University, No. 639 Zhizaoju Road, Shanghai 200011, P.R. China

*Corresponding author: Fax: +86 21 63011643; Tel: +86 21 63034903; E-mail: chendemin9999@163.com

$\dagger$ The two authors made equal contribution to the paper

Key Words: $\alpha$-Tricalcium Phosphate, $\beta$-Tricalcium Phosphate, Strontium, Bioactive bone cement, Phase transition setting.

\section{INTRODUCTION}

Calcium phosphate cements (CPCs) have been developed with good biocompatibility and bioactivity, which has received much attention in recently years ${ }^{1}$. All kinds of cements with different compositions have been prepared in order to conquer the disadvantages of traditional used polymethyl methacrylate (PMMA) bone cements, because of its non-degradable and non-resorbable properties, fast exothermic reaction, cardiopulmonary complications and aseptic loosening induced by its lack of adhesiveness to bone tissue $e^{2,3,4}$. On the other hand, the beneficial effect of strontium element by reduction of bone resorption and stimulation of bone formation has been recognized in the treatment of osteoporosis, especially senile ${ }^{5}$. In human tissue, strontium ion shares the similar physiological pathway as calcium ion and the substitution of calcium by strontium in apatite will cause lattice expansion due to the larger atomic radius of $\mathrm{Sr}$ than that of $\mathrm{Ca}$, which alters the physicochemical property and biocompatibility of the bioactive bone cement ${ }^{6,7}$. Recent developments have focused on injectable calcium phosphate cements for various applications in treatment of vertebral compression fractures or bone defects, but most of these bone cement have weak mechanical properties. Polymeric calcium phosphate cement having good mechanical properties (compressive strengths 50-80 MPa) similar to zinc polycarboxylate cements which would be worthy of further investigation ${ }^{8}$.

In the present study, the effect of various additives, citric acid, potassium citrate, strontium carbonate on the properties of the polycarboxylic acid-calcium phosphate cement bone cement were investigated in the hope of obtaining polyacidcalcium phosphate cements with more suitable bioactive and mechanical properties. Containing strontium 0, 5, 10, 15 and 20 atom \% bioactive bone cement were prepared. But there was an interesting phenomena i.e., the setting of the cement pastes occured in several minutes except the 20 atom $\% \mathrm{Sr} /(\mathrm{Sr}$ + Ca) sample which did not set even in $6 \mathrm{~h}$. Therefore, the main goal of the present study was to investigate the influence of Sr-substitutions on the setting of the bioactive bone cement. The presence of the foreign ions can alter a series of structural and physico-chemical properties of bioactive bone cement, such as lattice constants, crystal sizes and thermal stability. The effects of Sr content on the structure and vibrational modes of tricalcium phosphate/hydroxy apatite were also discussed.

\section{EXPERIMENTAL}

Preparation of the powder of cement: Stoichiometric amounts of $\mathrm{CaHPO}_{4} \cdot 2 \mathrm{H}_{2} \mathrm{O}$ (Fourth Reagent Plant Shanghai, China), $\mathrm{CaCO}_{3}$ (Si Lian Chemical Co. Ltd. Shanghai, China) and $\mathrm{SrCO}_{3}$ (THE First Reagent Plant Shanghai, China) were 
used to reach the respective compositions of $0,5,10,15$ and 20 atom \% of $\mathrm{Sr}$ replacing $\mathrm{Ca}$ in composition. The mixture were grinded by a QM-IF ball mill (Nanjing University Instrument Factory, China) at a low rotation speed (400 rpm) and heated at $1450{ }^{\circ} \mathrm{C}$ for $5 \mathrm{~h}$ and cooled slowly. The calcined cakes were milled and through a 200 mesh sieved and then were used as cement powders.

Preparation of the liquids of cement: Poly(acrylic acidco-itaconic acid) was synthesized as previously reported. Twenty five wt $\%$ citric acid, $5 \mathrm{wt} \%$ potassium citrate, $70 \mathrm{wt} \%$ poly(acrylic acid-co-itaconic acid (poly(AA-co-IA)) copolymer were mixed and dissolved ${ }^{9}$. Liquids to powder rates (LPR): $1.8: 1 \mathrm{~g} / \mathrm{g}$. Five kinds of cement were prepared by mixing the the powder of $0,5,10,15$ and 20 atom $\%$ and the liquids were mixed in the liquid/powder $=1: 1.8$.

The powder and cements were analyzed by X-ray diffraction (XRD, D/MAX 2550 VB/PC, Rigaku, Japan) using $\mathrm{CuK}_{\alpha}$ radiation from $2 \theta=10-80^{\circ}$, with a $2 \theta$-step of $0.02^{\circ}$. XRD patterns were recorded in an automatic diffractometer crystallographic identification of the phases of synthesized powders and the cement was accomplished by comparing the experimental XRD patterns with standards compiled by the Joint Committee on Powder Diffraction Standards (JCPDS). (HA, card\#09-432; $\alpha$-TCP, \#29-359; $\beta$-TCP, \#09-169).

The liquids, the powder and the cement were scanned by Fourier transform infrared spectroscopy apparatus. FTIR were measured on a Nicolet 5700 FT-IR spectroscope. All samples were taken from $\mathrm{KBr}$ pellets and with $0.09 \mathrm{~cm}^{-1}$ resolution. IR measurements were carried out at room temperature using the $\mathrm{KBr}$ pellet technique or liquid film method.

\section{RESULTS AND DISCUSSION}

Fig. 1 show the X-ray diffraction patterns of the five group of bioactive cement powders. Fig. 1a-d show the biphase of $\alpha$-TCP/HA. The diffraction patterns of the cement powders were slightly and continuously shift to lower diffraction angles as increasing strontium amounts till to 15 atom \% indicating that the changes in lattice parameters turned up because of the substitution of $\mathrm{Sr}$ for $\mathrm{Ca}$ in TCP/HA. But Fig. 1e show the characteric biphase of $\beta$-TCP/HA when strontium amount got to 20 atom $\%$. The presence of foreign ions strontium can replace calcium in TCP/HA biphase structure, while the relative variations of the cell parameters and the phase of TCP are quit different. Strontium can enter into the $\alpha$-TCP by substitution for calcium up to 15 atom $\% \mathrm{Sr} /(\mathrm{Sr}+\mathrm{Ca})$, causing a linear enlargement of the lattice constants. But when strontium content got to 20 atom $\% \mathrm{Sr} /(\mathrm{Sr}+\mathrm{Ca})$, the XRD patterns indicate that the phase of $\beta$-TCP emerged and the phase of $\alpha$-TCP disappeared. On the other hand, the phase of HA maintain stability while its cell parameters enlarged. The results confirm the formation of Sr-substituted TCP/HA biphase powders.the reaction may be represented by equation given below:

$$
\begin{gathered}
\mathrm{CaCO}_{3}+\mathrm{SrCO}_{3}+\mathrm{CaHPO}_{4} \cdot 2 \mathrm{H}_{2} \mathrm{O} \rightarrow \\
(\mathrm{Ca}+\mathrm{Sr})_{3}\left(\mathrm{PO}_{4}\right)_{2}+(\mathrm{Ca}+\mathrm{Sr})_{10}\left(\mathrm{PO}_{3}\right)_{6}(\mathrm{OH})_{2}
\end{gathered}
$$

$\beta$-TCP represents the form of tricalcium phosphate stable at temperatures lower than $1120^{\circ} \mathrm{C}$ and its crystallizes are in the rombohedral space group $\mathrm{R} 3 \mathrm{c}$. In present study, $\beta$-TCP phase may be formed at low temperature while phase transition from $\beta$-TCP intoa-TCP may take place at higher temperature.

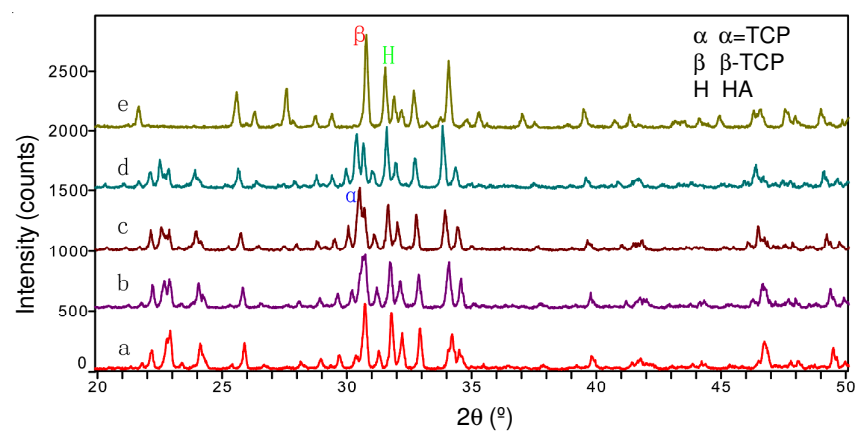

Fig. 1. X-Ray diffraction patterns of (a) 0 atom $\% \mathrm{Sr} /(\mathrm{Sr}+\mathrm{Ca})$, (b) 5 atom $\% \mathrm{Sr} /(\mathrm{Sr}+\mathrm{Ca}),($ c) 10 atom $\% \mathrm{Sr} /(\mathrm{Sr}+\mathrm{Ca})$, (d) 15 atom $\% \mathrm{Sr} /(\mathrm{Sr}+$ $\mathrm{Ca}),($ e) 20 atom $\% \mathrm{Sr} /(\mathrm{Sr}+\mathrm{Ca})$ cement powders

According the results of the XRD, the transformation from $\beta$ TCP phase to $\alpha$-TCP may be occured, even a series of $\operatorname{Sr}(0$, 5,10 and $15 \%$ ) are incorporated into it at high temperature. Strontium may enlarge the unit cell because strontium ion radius $(1.13 \AA)$ is bigger than that of calcium $(0.99 \AA)$. But, up to 20 atom $\% \mathrm{Sr} /(\mathrm{Sr}+\mathrm{Ca})$, the rombohedral space group $\mathrm{R} 3 \mathrm{c}$ of $\beta$ TCP does not transform to the monoclinic space group P21/ $\mathrm{a}(14)$ of $\alpha$-TCP at the temperature of $1450^{\circ} \mathrm{C}$, which suggests that srontium incorporation does not provoke a remarkable rearrangement of the unit cell of $\beta$-TCP even in higher temperature than $1120^{\circ} \mathrm{C}$. So strontium substitution for calcium may change the thermal stabilization of $\beta$-TCP.

At the same time, strontium can substitute for calcium in the hexagonal space group P63/m (176) of HA which is confirmed by Fig. 1. The diffraction patterns of the HA phase were also slightly and continuously shift to lower diffraction angles when mounting $\mathrm{Sr}$ amounts were introduced.

Figs. 2 and 3 show the variation of the lattice dimensions and the lattice volume of $\alpha-(\mathrm{Sr}, \mathrm{Ca}) \mathrm{TCP}$ and $(\mathrm{Sr}, \mathrm{Ca}) \mathrm{HA}$ with increasing $\mathrm{Sr}$ amounts. Rietveld refinement analyses performed on the powder data revealed an almost linear evolution of the lattice parameters. With the increase of $\mathrm{Sr}$ content, the lattice dimensions and lattice volume of $\alpha-(\mathrm{Sr}, \mathrm{Ca}) \mathrm{TCP}$ and $(\mathrm{Sr}$, $\mathrm{Ca}) \mathrm{HA}$ increased. It is clear that the incorporation of $\mathrm{Sr}$ in $\alpha$ TCP has led to a significant expansion in all the $\mathrm{a}, \mathrm{b}$ and $\mathrm{c}$ axis. The cell parameters (a, b, c, V) of HA vary nearly linearly with a series of strontium content including 20 atom \% Sr/( $\mathrm{Sr}$ $+\mathrm{Ca})$. The present method that $\mathrm{Sr} /(\mathrm{Sr}+\mathrm{Ca}),(\mathrm{Sr}+\mathrm{Ca}) / \mathrm{P}$ ratio can be controlled by proportionate weighing while common homogenization methods can be applied. The crystallinity of TCP/HA biphase bioactive cement powders is excellent as shown in Fig. 1.

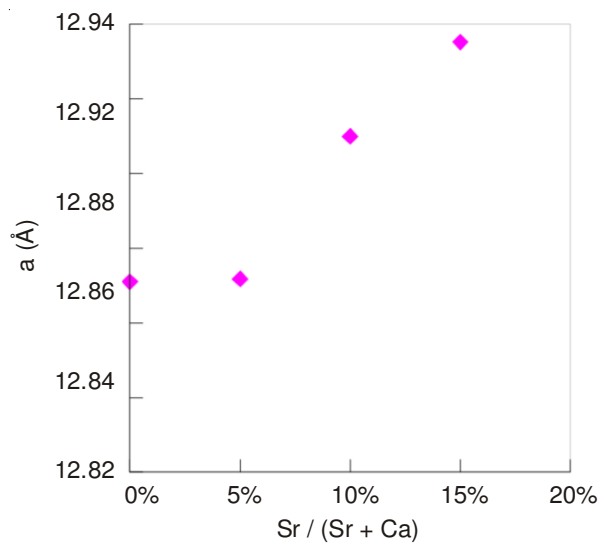



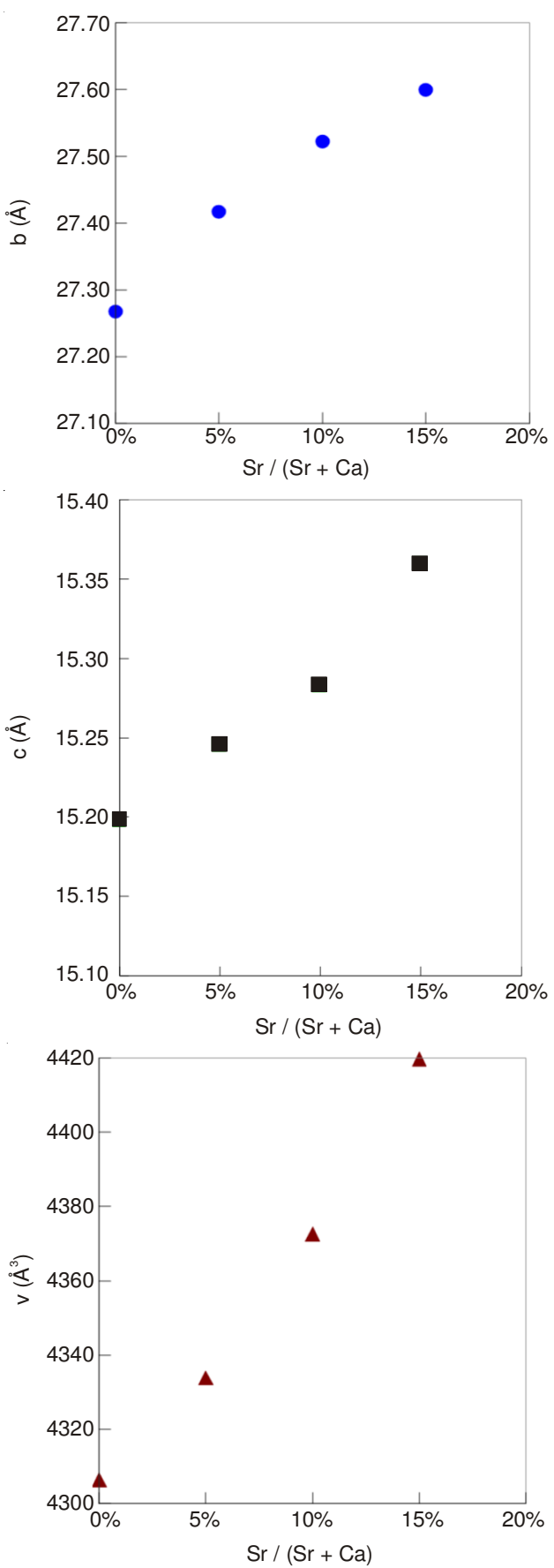

Fig. 2. Variation of the lattice of $\alpha-(\mathrm{Sr}, \mathrm{Ca}) \mathrm{TCP}$ with increasing $\mathrm{Sr}$ content

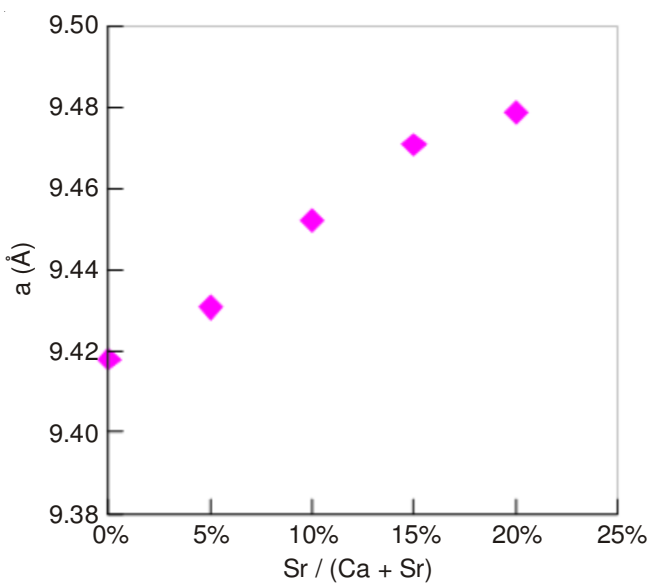

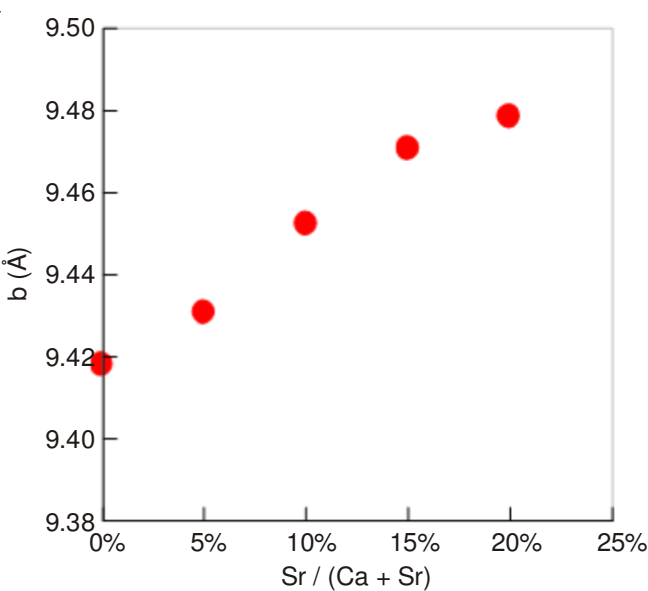
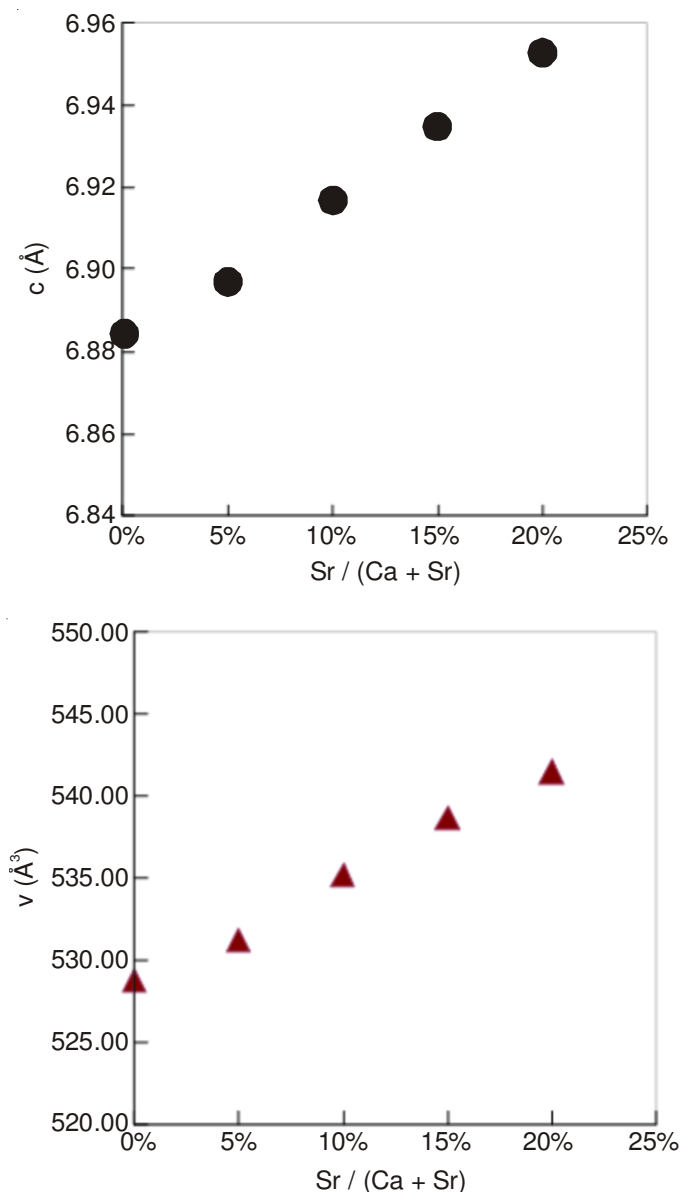

Fig. 3. Variation of the lattice of ( $\mathrm{Sr}, \mathrm{Ca}) \mathrm{HA}$ with increasing $\mathrm{Sr}$ content

Figs. 4 and 5 show the FTIR spectra of the cement powder with different content of strontium. The assignment of FTIR of cement powders is listed in Table- $1^{10,11}$.

FTIR spectra of the Sr series $(0,5,10$ and $15 \%)$ cement powder were assigned to the $\alpha$-TCP/HA. The spectra of $20 \%$ cement powder clearly shows the presence of bands at 1112 , 1082, 1037 and $1015 \mathrm{~cm}^{-1}$ can be assigned to $\mathrm{PO}_{4}{ }^{3-}$ bend $\left(\mathrm{V}_{3}\right)$ of $\beta$-TCP. $\mathrm{PO}_{4}{ }^{3-}$ bend $\left(\mathrm{V}_{1}\right)$ disappeared or weakened because wavenumber $962 \mathrm{~cm}^{-1}\left(\mathrm{HA} \mathrm{PO}_{4}{ }^{3-}\right.$ bend $\left.\left(v_{1}\right)\right)$; 972 and $945 \mathrm{~cm}^{-1}$ $\left(\beta\right.$-TCP $\mathrm{PO}_{4}{ }^{3-}$ bend $\left(v_{1}\right)$ ) were too close to merge together.

The assignment of FTIR of cement liquid, the reactive products of 0,10 and $20 \%$ cement powder is listed in Table- $2^{12-15}$. 
TABLE-1

ASSIGNMENT OF FTIR OF CEMENT POWDERS

\begin{tabular}{lccccccc}
\hline \multicolumn{1}{c}{ Assignment } & $\mathrm{OH}$ stretch & $\mathrm{PO}_{4}{ }^{3-}$ bend $\left(v_{3}\right)$ & $\mathrm{PO}_{4}{ }^{3-}$ bend $\left(\mathrm{v}_{3}\right)$ & $\mathrm{PO}_{4}{ }^{3-}$ bend $\left(v_{1}\right)$ & $\mathrm{PO}_{4}{ }^{3-}$ bend $\left(v_{4}\right)$ & $\mathrm{PO}_{4}{ }^{3-}$ bend $\left(v_{4}\right)$ & $\mathrm{PO}_{4}{ }^{3-}$ bend $\left(v_{2}\right)$ \\
\hline $0-15 \%$ Band $\left(\mathrm{cm}^{-1}\right)$ & $3569-3072$ & 1087 & $1045-1047$ & $956-958$ & $597-598$ & $558-568$ & 466 \\
$20 \%$ Band $\left(\mathrm{cm}^{-1}\right)$ & 3572 & 1082,1112 & 1037,1035 & - & 601 & 551 & 469 \\
\hline
\end{tabular}

TABLE-2

ASSIGNMENT OF FTIR OF CEMENT LIQUID, THE REACTIVE PRODUCTS OF 0, 10 AND $20 \%$ CEMENT POWDER

\begin{tabular}{|c|c|c|c|c|c|c|c|}
\hline \multicolumn{2}{|c|}{ Liquids } & \multicolumn{2}{|c|}{$0 \%$} & \multicolumn{2}{|c|}{$10 \%$} & \multicolumn{2}{|c|}{$20 \%$} \\
\hline COO-salt & 1574 & COO-salt & 1580,1421 & COO-salt & 1578,1418 & COO-salt & 1573,1457 \\
\hline $\mathrm{C}=\mathrm{C}$ & 1407 & $\mathrm{PO}_{4}{ }^{3-}$ bend $\left(v_{3}\right)$ & 1045,1090 & $\mathrm{PO}_{4}{ }^{3-}$ bend $\left(\mathrm{v}_{3}\right)$ & $1089,1068,1049$ & $\mathrm{PO}_{4}{ }^{3-}$ bend $\left(\mathrm{v}_{3}\right)$ & 1039 \\
\hline C-O stretching & 1201 & $\mathrm{PO}_{4}{ }^{3-}$ bend $\left(\mathrm{v}_{4}\right)$ & 598,596 & $\mathrm{PO}_{4}^{3-}$ bend $\left(\mathrm{v}_{4}\right)$ & 598,565 & $\mathrm{PO}_{4}{ }^{3-}$ bend $\left(\mathrm{v}_{4}\right)$ & 600,551 \\
\hline $\mathrm{COOH}$ & 1727 & - & - & - & - & $\mathrm{COOH}$ & 1719 \\
\hline
\end{tabular}

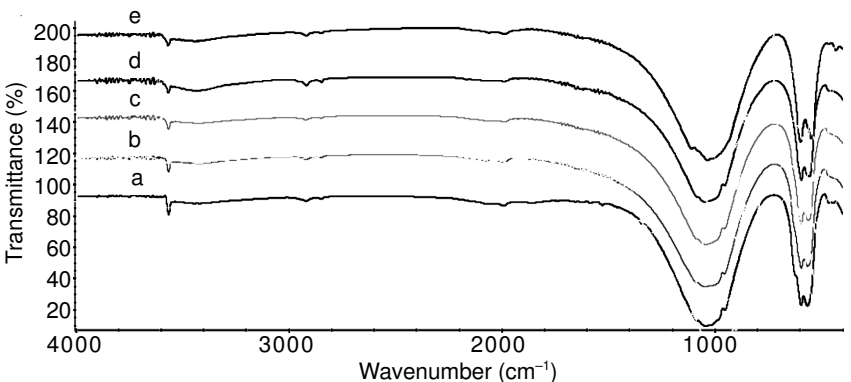

Fig. 4. FTIR spectra of the powder of cement with diferent content of strontium. a, b, c, d, e meant the $\mathrm{Sr} /(\mathrm{Sr}+\mathrm{Ca})$ atom ratio of $0,5,10$, 15 and $20 \%$, respectively

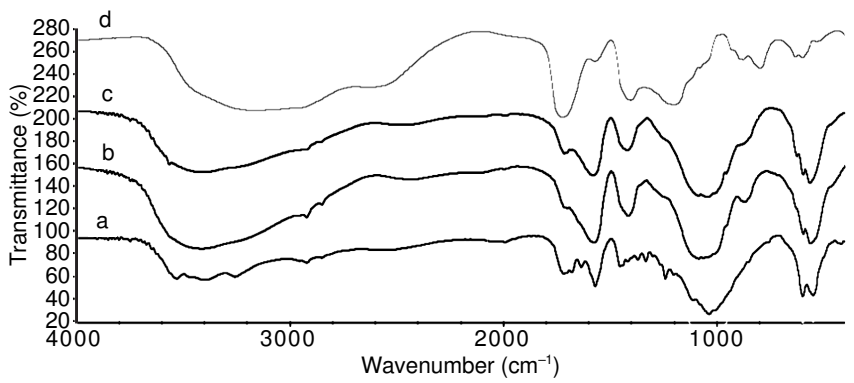

Fig. 5. FTIR spectra of the liquid and the hydrated cement. e meant the cement liquid. a, b, c meant 20, 10 and $0 \%$ hydrated cement group, respectively.

In The FTIR spectra of liquid, the wavenumber of 1727 and $1574 \mathrm{~cm}^{-1}$ were assigned to carboxylic acid, citric salt adsorbing band, respectively. The set products of the 0 and $10 \%$ group cement showed two characteristic FTIR absorption bands at 1580 and $1420 \mathrm{~cm}^{-1}$ which were assigned to a carboxylic acid salt. FTIR spectra analyses revealed the presence of a polycarboxylate salt product. A small amount of unreacted polycarboxylic acid was also observed in the hardened cement. FTIR spectra of $20 \%$ group shows unreacted polycarboxylic acid existed (wavenumber $1719 \mathrm{~cm}^{-1}$ ) and near wavenumber 1420 emerged lots of small split adsorb peak, which may show that $\beta$-TCP or HA partially involved in the chemical reaction.

Characterization of the bioactive cement: X-Ray diffraction patterns for cement with a series of strontium amount are shown in Figs. 6 and 7. The diffraction pattern for the cement 0, 5, 10 and $15 \%$ samples (Fig. 6a-d) show a typical HA identity. Compared to corresponding powder, the crystallinity of the cement appears to be lower, as shown by the broadening and the decrease in intensity of the XRD signals. It should

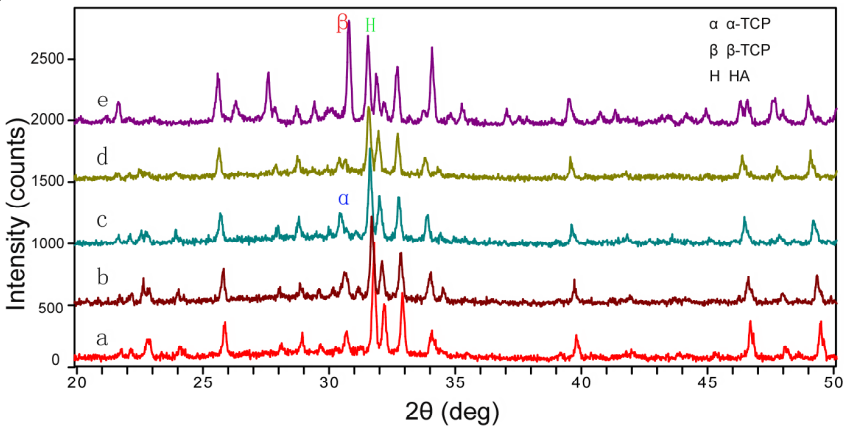

Fig. 6. X-Ray diffraction patterns of a $0 \%$ Sr-cement b $5 \%$ Sr- cement c $10 \%$ Sr- cement d $15 \%$ Sr-cement e $20 \%$ Sr- cement

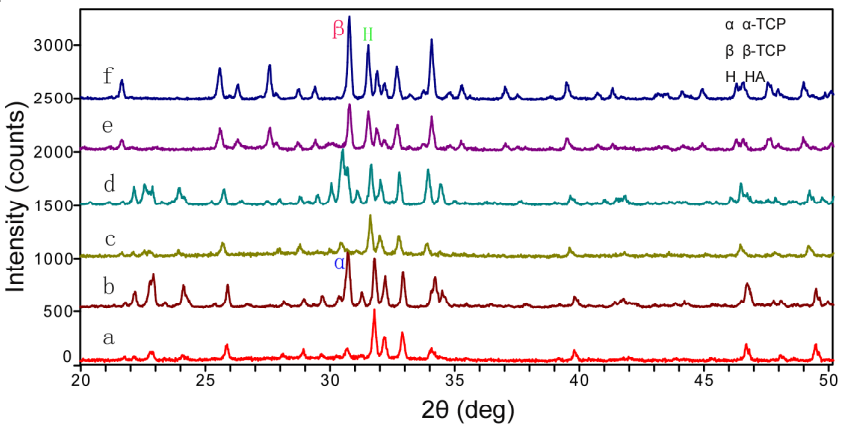

Fig. 7. Comparation of X-ray diffraction patterns between cement and powder. a, c, e represent 0,10 and $20 \%$ Sr of cement, respectively. $\mathrm{b}, \mathrm{d}, \mathrm{f}$ represent 0,10 and $20 \%$ sr of powder, respectively

be noticed that much lower peaks of $\alpha$-TCP is observed in the $\mathrm{X}$-ray diffraction patterns and also shows that there exist small amount of unreacted $\alpha$-TCP phase which demonstrate that the cement is still not fully set. Although details of the polycarboxylate conformation in the cements cannot be determined from the XRD data, it should affect the crystallinity of reactant which can be demonstrated by compareing with the powder and the corresponding cement in Fig. 7. The broadness of the peaks which may be due to the low crystllinity or the small crystallite size of the new formed HA might represent small amount of $\alpha$-TCP, indicating that a majority of $\alpha$-TCP was consumed in forming the cement, which has been observed in FTIR spectrum. Chelation is also known as calcium bridge formation which occurs between surface calcium atoms of HA and carboxylate groups of (poly(AA-co-IA). X-Ray diffractin patterns of Fig. 7e show that the cement group of 20 atom $\%$ $\mathrm{Sr}$ amount, which still keeps the biphase structure of $\beta$-TCP/ HA.The characteristic peaks of the $\beta$-TCP/HA was almost in 
accord with the peaks of corresponding powder except the intensity became weaker becaus of the impact of the polycarboxylate, which also show that $\beta$-TCP has no character of hydration.

The polymeric calcium phosphate cements set as the result of two reactions, the typical acid-base reaction and a polymerization reaction of polymer monomers ${ }^{16}$. The reaction product, that is the polysalt derived from the reaction of poly(AA-co-IA) copolymer and critic acid, with the $\alpha$-TCP/ HA powder, forms a cement matrix analogous to that formed in polycarboxylate zinc cement ${ }^{8}$. But $\beta$-TCP has no selfharding property although It is finally dried ${ }^{17}$. The manipulation of the setting times of bioactive bone cement is significant as they should meet the requirements of surgical procedures. So it can not be put into practical clinic use because the set time is too long.

\section{Conclusion}

Strontium containing $\alpha$-TCP/HA biphase bioactive bone cement powders could be prepared at $1450{ }^{\circ} \mathrm{C} .20 \%$ atom $\mathrm{Sr} /(\mathrm{Sr}+\mathrm{Ca})$ powder of $\beta$-TCP/HA was not suit for preparing bioactive bone cement.

\section{ACKNOWLEDGEMENTS}

This work was supported by grants from National Natural Science Foundation of China (No. 30470480) and Shanghai Leading Academic Discipline Project (No. S30206, T0202).

\section{REFERENCES}

1. B.W. Brown and L.C. Chow, Dental Resptorative Cement Pastes, US Patent 4518430 (1985).

2. G. Dagang, X. Dagang and L. Yaxiong, Mater. Med., 21, 1927 (2010).

3. M.P. Ginebra, M. Espanol, E.B. Montufar, R.A. Perez and G. Mestres, Acta Biomater., 6, 2863 (2010).

4. I.H. Lieberman, D. Togawa and M.M. Kayanja, Spine J. Official J. North Am. Spine Soc., 5, 305S (2005).

5. P.J. Marie, Bone, 38, S10 (2006).

6. S. Pors Nielsen, Bone, 35, 583 (1985).

7. X. Wang and J. Ye, Mater. Med., 19, 1183 (2008).

8. Y. Matsuya, J.M. Antonucci, S. Matsuya, S. Takagi and L.C. Chow, Dental Mater. Official Pub. Acad. Dental Mater., 12, 2 (1996).

9. D.M. Chen, Chin. J. Dental Mater. Devices, 8, 118 (1999).

10. I. Manjubala, Mater. Chem. Phys., 71, 272 (2001).

11. Y. Li, F. Kong and W. Weng, J. Biomed. Mater. Res. B Appl. Biomater, 89B, 508 (2009).

12. J.-S. Weng, S.-C. Liou and S.-Y. Chen, Biomaterials, 25, 3155 (2004).

13. Y. Park, S. Ryu, S. Yoon, R. Stevens and H. Park, Mater. Chem. Phys., 109, 440 (2008).

14. J. Pena and M. Vallet-Regi, ChemInform, 34, 1687 (2003).

15. S. Meejoo, W. Maneeprakorn and P. Winotai, Thermochim. Acta, 447, 115 (2006).

16. R.M. Khashaba, M. Moussa, C. Koch, A.R. Jurgensen, D.M. Missimer, R.L. Rutherford, N.B. Chutkan and J.L. Borke, Int. J. Biomater, 2010, 467641 (2010).

17. T. Shiotsu, Surgical Cement Containing $\alpha$-Tricalcium phosphate, Poly(carboxylic acid) and Water, US Patent 4677140 (1987). 